\title{
Effect of cold stress on boro rice seedlings
}

\author{
Kumari Priyanka* and H. K. Jaiswal \\ Department of Genetics and Plant Breeding, Institute of Agricultural Sciences, Banaras Hindu University, Varanasi \\ - 221005 (Uttar Pradesh), INDIA \\ *Corresponding author. E-mail: kpriyanka.choudhary@gmail.com
}

Received: October 6, 2016; Revised received: February 7, 2017; Accepted: May 9, 2017

\begin{abstract}
Cold stress at seedling stage is a major constraint in boro rice production. Nine boro rice lines were crossed in diallel fashion excluding reciprocals to obtain 36 crosses. All the 36 crosses along with parents were grown in nursery in three seasons (boro-2014, kharif-2015 and boro-2015). Performance of seedlings for survival per cent, chlorophyll content, relative water content, membrane stability index was recorded just before transplanting in all the three seasons. Scoring for cold tolerance was done in both boro seasons. Gautam showed highest survival rate over three seasons. Among crosses, IR 64 x Krishna Hamsa showed highest survival (84\%) in boro-2014, MTU 1010 x Jaya (86.33\%) in boro-2015 and MTU 1010 x Krishna Hamsa (95.67\%) in kharif-2015. Jaya x Krishna Hamsa was most cold tolerant cross over both boro seasons. Significant positive correlation was observed among survival per cent, chlorophyll content, relative water content and membrane stability index over seasons.
\end{abstract}

Keywords: Chlorophyll content, Cold tolerance, Membrane stability index, Relative water content, Seedlings

\section{INTRODUCTION}

Temperature affects growth and development of a rice plant by influencing various physiological processes at cell, tissue and organ level. Yoshida (1981) reported that $10{ }^{\circ} \mathrm{C}$ is the minimum critical temperature below which rice does not germinate. Cold stress in rice delays germination and emergence and ultimately survival per cent. The critical temperature for root development is 12 to $16{ }^{\circ} \mathrm{C}$, for shoot development is 7 to 16 ${ }^{\circ} \mathrm{C}$ and for shoot and root development is $10{ }^{\circ} \mathrm{C}$ (Basuchaudhuri, 2014). Boro rice may suffer from low temperature stress as the nursery is grown in the cold months of November. Generally, the nursery of boro rice remains in field for more than two months i.e. from mid November to January. The harvesting of boro rice is done in last week of April (for early varieties) to June (for late varieties). So, boro rice may be affected by low temperature stress during seedling stage and by high heat stress during reproductive stage. Cold tolerance at seedling stage enable plants to produce more than suceptible genotypes as higher survival per cent of genotypes at seedling stage ensure optimum plant population in field.

Keeping in view the above mentioned facts, an experiment was conducted to find out the survival per cent, chlorophyll content, relative water content, membrane stability index and screen out cold tolerant genotypes at seedling stage.

\section{MATERIALS AND METHODS}

The nine varieties of rice (IR 8, IR 36, IR 64, HUR 36,
HUR 105, MTU 1010, Jaya, Krishna Hamsa and Gautam) were crossed in diallel mating design excluding reciprocals to obtain 36 crosses. All the 36 crosses along with 9 parents were evaluated for survival per cent, chlorophyll content, relative water content, membrane stability index at seedling stage in three seasons i.e. boro-2014, kharif-2015 and boro-2015 and scoring for cold tolerance was done for both boro seasons at Agricultural Research Farm of Banaras Hindu University.

Seeds were soaked in water overnight and then kept in moistened gunny bags for two days for sprouting. These sprouted seeds were spread uniformily on prepared seed bed in last week of November in boro seasons (boro-2014 and boro-2015) so that the genotypes faced low temperature at seedling stage. The data was recorded just before uprooting the seedlings for transplanting at 60 DAS, according to the Standard Evaluation System for Rice (IRRI, 2002). The scale for seedling cold tolerance ranged from 1-9 in which 1- dark green seedlings, 3- light green seedlings, 5- yellow seedlings, 7- brown seedlings and 9-dead seedlings. In kharif-2015, sowing was done in mid of June and 21 days seedlings were transplanted in field. The data on given traits was recorded just before transplanting to compare it with boro seasons. Data on cold tolerance was not recorded in kharif season as there is no issue of cold stress in kharif unlike boro seasons. Chlorophyll content of leaf was measured in the nursery with the help of SPAD - 502 Chlorophyll meter. Relative water content (RWC) was calculated using the method of Mata and Lamattina (2001). 
$\mathrm{RWC}(\%)=(\mathrm{FW}-\mathrm{DW}) /(\mathrm{TW}-\mathrm{DW}) \times 100$

Where, fresh weight (FW) and dry weight (DW) were obtained after drying the samples at $80{ }^{\circ} \mathrm{C}$ for at least $48 \mathrm{~h}$. Turgor weight (TW) was determined by subjecting leaves to rehydration for $2 \mathrm{~h}$.

The membrane stability index (MSI) was determined indirectly by measuring the electrical conductivity following the protocol of Sairam et al. (2002). The conductivity was determined using a conductivity meter (ELICO CM 180). Leaf samples (0.2 g) were placed in $30 \mathrm{ml}$ of distilled water in two sets. One set was kept at $40{ }^{\circ} \mathrm{C}$ for $30 \mathrm{~min}$ and then its conductivity (C1) was recorded using a conductivity meter. The second set was kept in a boiling water bath $\left(100{ }^{\circ} \mathrm{C}\right)$ for $15 \mathrm{~min}$ and its conductivity was also recorded (C2). The calculation of Membrane Stability Index was done using the formula,

$\mathrm{MSI}=[1-(\mathrm{C} 1 / \mathrm{C} 2)] \mathrm{X} 100$

Statistical analysis was performed with the help of statistical software MS Excel (2007) and IBM SPSS Statistics 20.

\section{RESULTS AND DISCUSSION}

Rice is an important crop sensitive to different type of abiotic stresses. Pathak et al. (1999) reported that cold stress at seedling stage leads to poor germination, poor vigor, stunted seedling growth, seedling chlorosis and seedling mortality. Analysis of variance for survival per cent, chlorophyll content, relative water content (RWC) and membrane stability index (MSI) was done for three growing seasons (boro-2014, boro-2015 and kharif-2015) separately. It showed significant variations among genotypes in three different seasons (Table 1). In the present investigation, December and January remained the coldest month in both boro seasons during nursery raising period. In these two months, the minimum temperature fell below the critical temperature required for rice germination. The optimum range for germination and early seedling growth of rice is $25-30^{\circ} \mathrm{C}$, which is attained in kharif season. Boro rice is adversely affected by low temperature in its vegetative stage. Leaf yellowing score is

Table 1. Analysis of variance over seasons (boro-2014, boro-2015 and kharif-2015) for given traits of rice.

\begin{tabular}{lllllll}
\hline SV & DF & Season & SP & CHL & RWC & MSI \\
\hline Replication & 2 & B-2014 & 1.12 & 0.24 & 0.40 & 1.26 \\
& & B-2015 & 1.81 & 0.54 & 0.27 & 0.19 \\
Treatment & & K-2015 & 2.72 & 0.34 & 0.13 & 0.01 \\
& 44 & B-2014 & $218.66^{* * *}$ & $18.11^{* * *}$ & $209.01^{* * *}$ & $223.33^{* * * *}$ \\
& & B-2015 & $324.75^{* * *}$ & $15.31^{* * *}$ & $196.64^{* * *}$ & $184.81^{* * *}$ \\
Error & & K-2015 & $43.92^{* * *}$ & $7.59^{* * *}$ & $204.65^{* * *}$ & $76.84^{* * *}$ \\
& \multirow{2}{*}{88} & B-2014 & 1.63 & 2.63 & 0.39 & 0.84 \\
& & B-2015 & 1.77 & 0.47 & 0.24 & 0.14 \\
\hline
\end{tabular}

${ }^{*} \mathrm{p}<0.05 ;{ }^{* *} \mathrm{p}<0.01 ; * * * \mathrm{p}<0.001 ; \mathrm{SV}-$ Source of variation; DF - Degrees of freedom; SP- Survival \%, CHL-Chlorophyll content, RWC- Relative water content, MSI-Membrane stability index

Table 2. Rice genotypes scored for cold tolerance over two boro seasons (boro- 2014 and boro- 2015).

\begin{tabular}{|c|c|}
\hline Score & Genotypes (boro-2014) \\
\hline 1 & Jaya x Krishna Hamsa, Krishna Hamsa x Gautam \\
\hline 3 & $\begin{array}{l}\text { HUR 36, Jaya, Krishna Hamsa, Gautam, IR8 x Jaya, IR } 36 \text { x MTU 1010, IR 64x MTU 1010, IR } 64 \text { X Jaya, IR } 64 \text { x } \\
\text { Krishna Hamsa, MTU } 1010 \text { x Jaya, MTU } 1010 \text { x Krishna Hamsa, Jaya x Krishna Hamsa }\end{array}$ \\
\hline 5 & $\begin{array}{l}\text { IR 64, HUR 105,MTU1010, IR } 8 \text { x IR 36, IR } 8 \text { x MTU 1010, IR } 36 \text { x IR 64, IR } 36 \text { x HUR 105, IR } 36 \text { x Jaya, IR } 36 \text { x } \\
\text { Krishna Hamsa, HUR } 105 \text { x MTU 1010, HUR } 105 \text { x Jaya, HUR } 105 \text { x Gautam, MTU } 1010 \text { x Gautam }\end{array}$ \\
\hline 7 & $\begin{array}{l}\text { IR 8, IR 36, IR } 8 \text { x IR 64, IR } 8 \text { x IR 64, IR } 8 \text { x Krishna Hamsa, IR } 36 \text { X HUR 36, IR } 36 \text { x Gautam,IR } 64 \text { x HUR } 105 \text {, } \\
\text { IR } 64 \text { x Gautam, HUR } 36 \text { x HUR 105, HUR } 36 \text { x Jaya, HUR 36x Krishna Hamsa, HUR } 36 \text { x Gautam, HUR } 105 \text { x } \\
\text { Krishna Hamsa }\end{array}$ \\
\hline 9 & $\begin{array}{l}\text { IR } 8 \text { x HUR 105,IR } 8 \text { x Gautam, IR } 64 \text { x HUR 36, HUR } 36 \text { x MTU } 1010 \\
\text { Genotypes (boro-2015) }\end{array}$ \\
\hline 1 & Jaya x Krishna Hamsa, Jaya x Gautam \\
\hline 3 & $\begin{array}{l}\text { Gautam, IR } 8 \text { x Jaya, IR } 36 \text { x Krishna Hamsa, IR } 64 \text { x Krishna Hamsa, MTU } 1010 \text { x Krishna Hamsa, MTU } 1010 \text { x } \\
\text { Gautam, Krishna Hamsa x Gautam }\end{array}$ \\
\hline 5 & $\begin{array}{l}\text { HUR 36, HUR 105, MTU 1010, Jaya, Krishna Hamsa, IR8 x IR 36, IR } 8 \text { x Krishna Hamsa, IR } 36 \text { x IR 64, IR } 64 \text { x } \\
\text { MTU 1010, IR } 64 \text { x Jaya, IR } 64 \text { x Gautam, HUR } 36 \text { x HUR 105,HUR } 105 \text { x MTU 1010,HUR } 105 \text { x Krishna Hamsa, } \\
\text { MTU } 1010 \text { x Jaya }\end{array}$ \\
\hline 7 & $\begin{array}{l}\text { IR 8, IR 36, IR 64, IR } 8 \text { x HUR 105, IR } 8 \text { x MTU1010, IR } 8 \text { x Gautam, IR } 36 \text { x HUR36, IR } 36 \text { x HUR 105, IR } 36 \text { x } \\
\text { MTU 1010, IR } 36 \text { x Jaya, HUR } 36 \text { x Jaya, HUR } 105 \text { x Gautam, HUR } 105 \text { x Jaya, IR } 36 \text { x Gautam, IR } 64 \text { x HUR 36, } \\
\text { IR } 64 \text { x HUR 105, HUR } 36 \text { x MTU 1010, HUR } 36 \text { x Krishna Hamsa, HUR } 36 \text { x Gautam }\end{array}$ \\
\hline 9 & IR 8 x IR 64, IR 8 x HUR 36 \\
\hline
\end{tabular}


Table 3. Correlation studies between Survival per cent, Chlorophyll content, Relative water content and Membrane stability index in rice seedlings over seasons.

\begin{tabular}{|c|c|c|c|c|c|}
\hline \multirow{5}{*}{ Boro-2014 } & & SP & CHL & RWC & MSI \\
\hline & SP & 1 & & & \\
\hline & CHL & $0.517 * *$ & 1 & & \\
\hline & RWC & $0.616^{* *}$ & $0.453 * *$ & 1 & \\
\hline & MSI & $0.458 * *$ & $0.363^{*}$ & $0.902 * *$ & 1 \\
\hline \multirow{4}{*}{ Boro-2015 } & SP & 1 & & & \\
\hline & CHL & $0.596 * *$ & 1 & & \\
\hline & RWC & $0.569 * *$ & $0.540 * *$ & 1 & \\
\hline & MSI & $0.344^{*}$ & $0.411 * *$ & $0.847 * *$ & 1 \\
\hline \multirow{4}{*}{ Kharif-2015 } & SP & 1 & & & \\
\hline & CHL & $0.647 * *$ & 1 & & \\
\hline & RWC & $0.705 * *$ & $0.601 * *$ & 1 & \\
\hline & MSI & $0.635^{* *}$ & $0.420^{* *}$ & $0.696^{* *}$ & 1 \\
\hline
\end{tabular}

**significant at 0.01 level; *significant at 0.05 level; SP- Survival \%; CHL-Chlorophyll content; RWC- Relative water content; MSI-Membrane stability index

most widely used technique for screening cold tolerant rice seedlings in nursery (Dutta and Pathak, 2007; Priyanka et al., 2015). Most of the genotypes showed differential performance over seasons (Table 2). Among parents, Gautam was scored as cold tolerant over seasons (boro-2014 and boro-2015). Among crosses, Jaya x Krishna Hamsa recorded best score for cold tolerance over both boro seasons. Besides this, IR 8 x Jaya, IR 64 x Krishna Hamsa and MTU 1010 x Krishna Hamsa also showed tolerance towards cold over both seasons. Parents and Crosses which recorded 1 and 3 scores were cold tolerant and moderately cold tolerant respectively (Table 2). These can be used as breeding materials in boro season where cold stress is a major problem in vegetative stage. Susceptible seedlings turned brownish and dead. Hence, the survival per cent of seedlings decreased.

Under severe cold conditions, rice seedlings fail to survive. In present study, survival percentage was recorded (Fig.1) in all the three seasons (boro-2014, boro2015 and kharif-2015). It was found that low temperature stress at seedling stage caused decrease in final survival percentage. Among parental genotypes, the survival ranged from $63 \%$ (IR 36) to $84.33 \%$ (Gautam) in boro-2014, $64 \%$ (IR 36) to $86 \%$ (Gautam) in boro-2015, and $81.67 \%$ (HUR 36) to

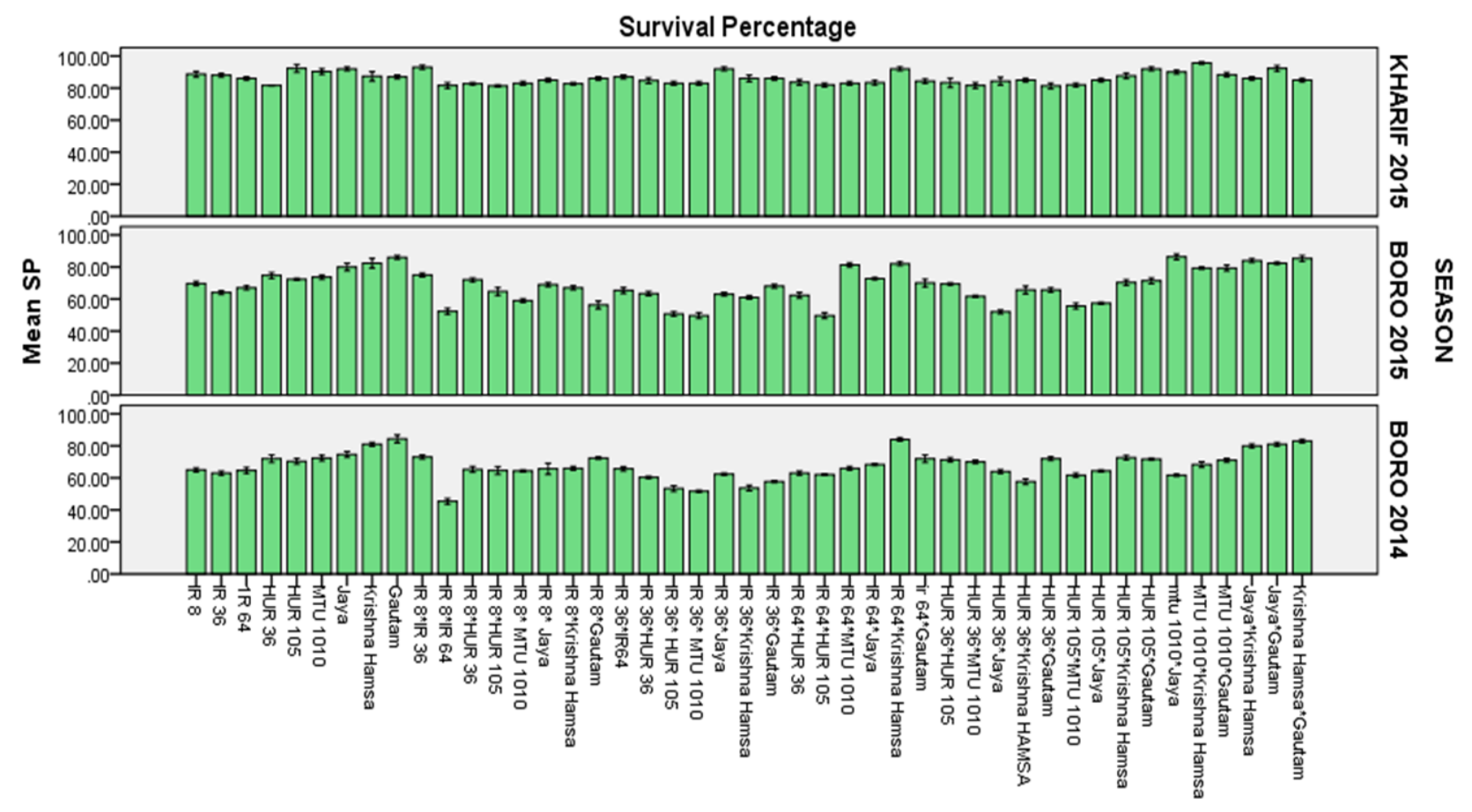

GENOTYPES

Error bars: +/- $2 \mathrm{SE}$

Fig. 1. Survival per cent of parents and crosses over three seasons. 


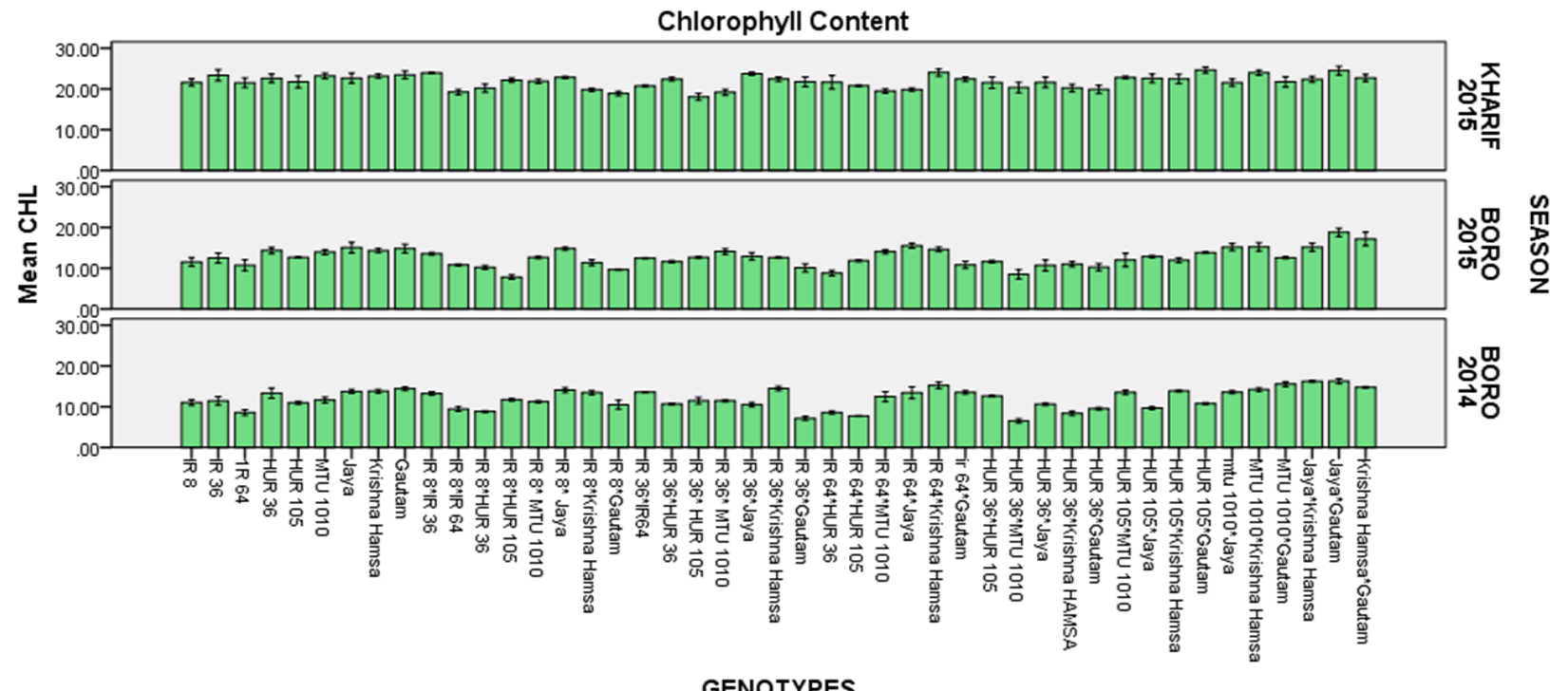

GENOTYPES

Fig. 2. Chlorophyll content of parents and crosses over three seasons.

$92.33 \%$ (HUR 105) in kharif-2015. Among parents, Gautam showed highest survival $84.33 \%$ (in boro2014) and $86 \%$ (in boro-2015). In kharif-2015 the same variety showed higher survival $(87 \%)$.Among crosses, survival \% ranged from $45.33 \%$ (IR $8 \times$ IR 64) to $84 \%$ (IR $64 \times$ Krishna Hamsa) in boro-2014, $49.67 \%$ (IR $36 \times$ MTU 1010) to $86.33 \%$ (MTU 1010 $\mathrm{x}$ Jaya) in boro-2015 and $81.33 \%$ (IR 8 x HUR 105 and HUR $36 \times$ Gautam) to $95.67 \%$ (MTU $1010 \times$ Krishna Hamsa) in kharif-2015. Among crosses, IR 64 $\mathrm{x}$ Krishna Hamsa showed highest survival (84\%) in boro-2014, MTU 1010 x Jaya (86.33\%) in boro-2015 and MTU 1010 x Krishna Hamsa (95.67 \%) in kharif2015. The genotypes and crosses showed better sur- vival per cent in kharif-2015 than boro seasons (boro2014 and boro-2015) as they got favourable temperature for growth and development. The mean survival percent of parents and crosses in kharif-2015 (85.74 $\%)$ was higher than both boro seasons $(67.43 \%$ in boro-2014 and $68.66 \%$ in boro-2015). The low survival per cent of genotypes in boro seasons may be due to cold stress (Fig.1). Survivality of seedlings are important to attain an optimum plant population in field. So, in boro season, seed rate should be high enough to obtain sufficient seedlings at the time of transplanting. Chlorophyll content of seedlings before transplanting was measured by SPAD (Fig. 2). Among parental genotypes, Gautam followed by Krishna Hamsa and Jaya

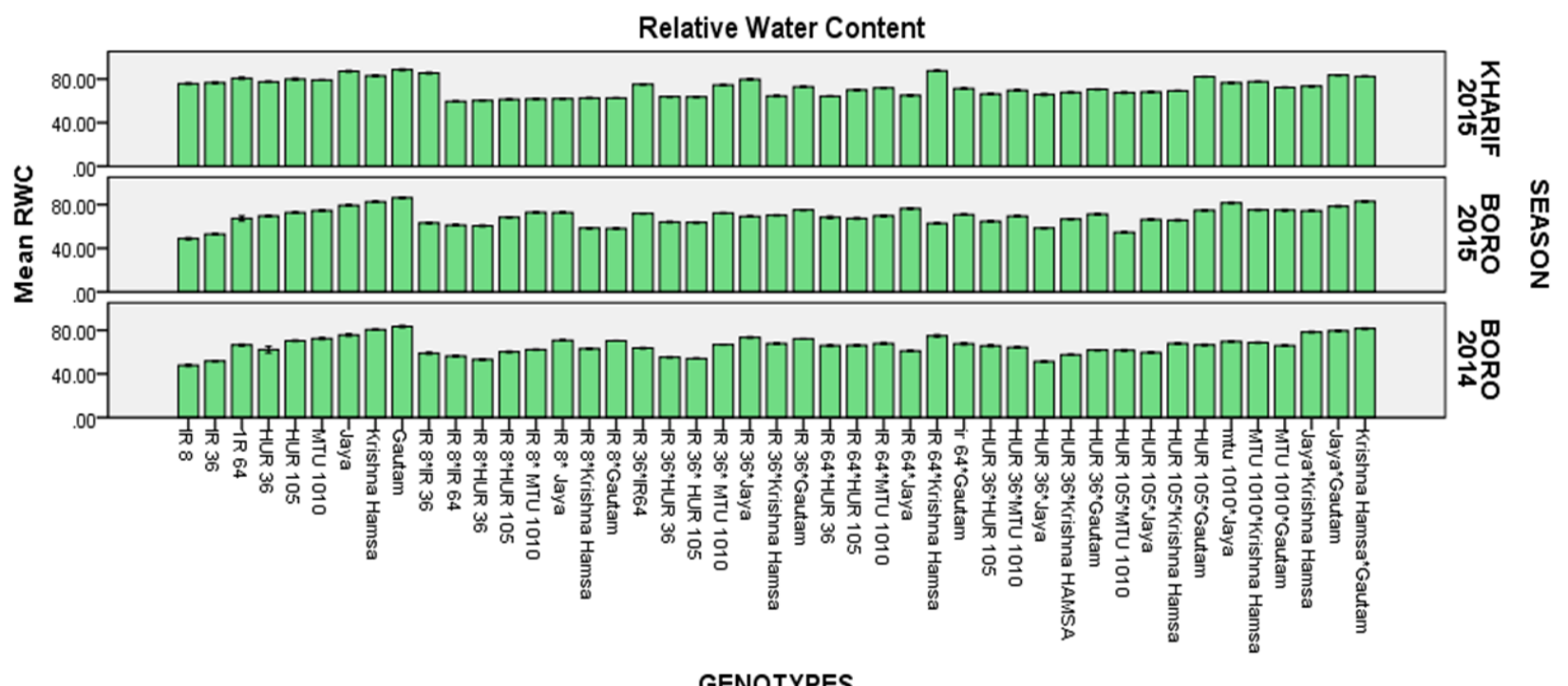

Error bars: +/- 2 SE

Fig. 3. Relative water content of parents and crosses over three seasons. 


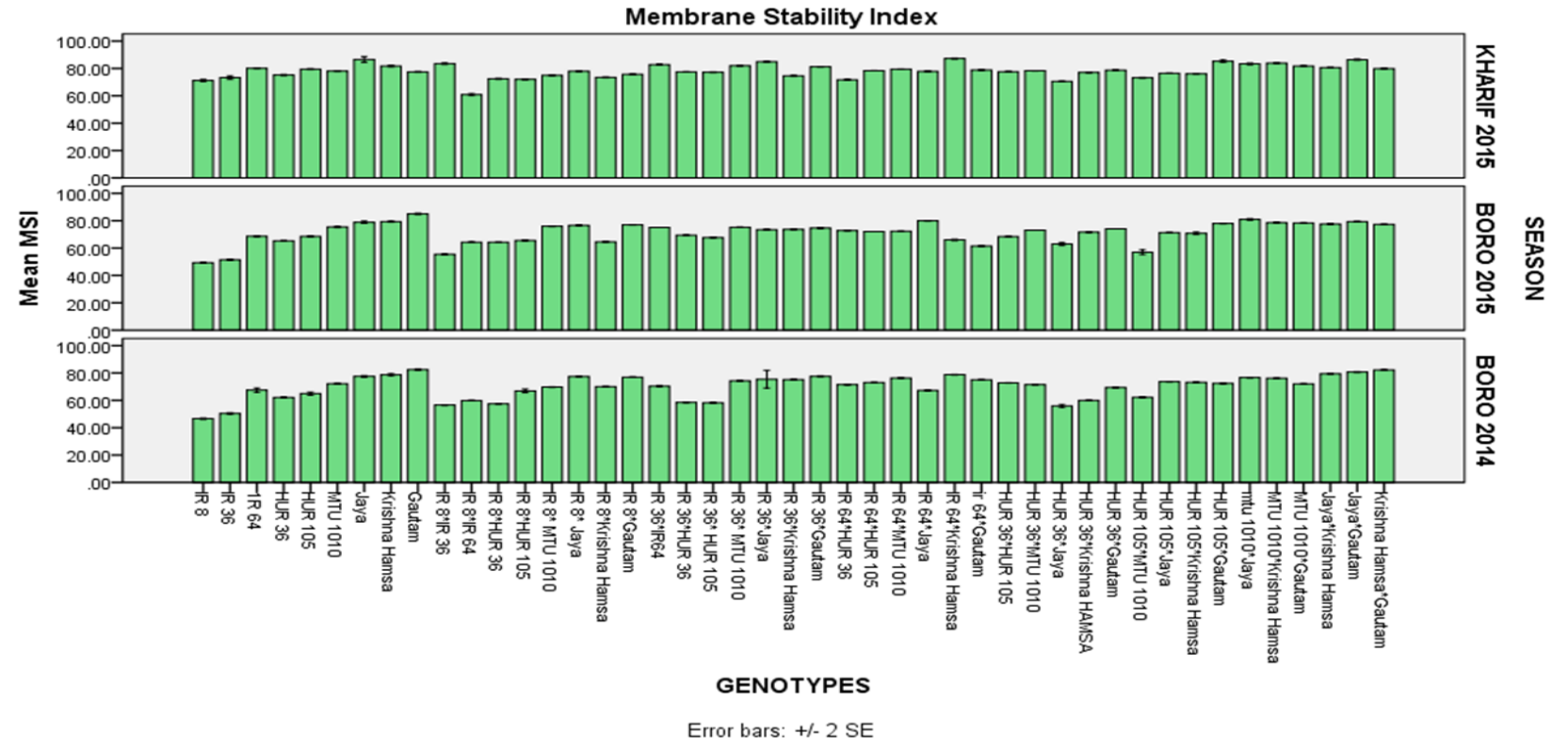

Fig. 4. Membrane stability index of parents and crosses over three seasons.

exhibited highest chlorophyll content in boro-2014, Jaya followed by Gautam and HUR 36 in boro-2015, whereas Gautam followed by IR 36 x MTU 1010 in kharif-2015. In crosses, the chlorophyll content ranged from 6.51 (HUR $36 \times$ MTU 1010) to 16.27 (Jaya $x$ Gautam) in boro-2014, 7.83(IR $8 \times$ HUR 105) to 18.8 (Jaya x Gautam) in boro-2015 and 18.06 (IR 36 x HUR 105) to 24.63 (HUR $105 \times$ Gautam) in kharif2015. The mean performance in kharif-2015 (21.82) was better than boro-2014 (11.95) and boro-2015 (12.66). Low temperature stress significantly reduces chlorophyll concentration in susceptible rice genotypes (Aghaee et al., 2011 and Jan et al., 2015). Yadegari et al. (2007) also reported that cold stress affects chlorophyll content in soybean. In the present study, the mean chlorophyll content of parents and crosses were significantly lower in both boro seasons than in kharif season (Fig. 2). Low temperature during seedling growth in boro season might have caused low photosynthetic rate hence low chlorophyll content than kharif season.

Among parental genotypes, Gautam exhibited highest RWC (relative water content) in all the three seasons i.e. $83.47 \%$ in boro-2014, $86.30 \%$ in boro-2015 and $88.59 \%$ in kharif-2015. Among crosses, the RWC (relative water content) ranged from 51.29\% (HUR 36 $\mathrm{x}$ Jaya) to $81.51 \%$ (Krishna Hamsa $\mathrm{x}$ Gautam) in boro $-2014,58.18 \%$ (IR $8 \times$ Gautam) to $82.90 \%$ (Krishna Hamsa x Gautam) in boro-2015 and $59.53 \%$ (IR 8 x IR 64) to $87.51 \%$ (IR $64 \times$ Krishna Hamsa) in kharif2015. The mean performance of kharif-2015 (72.46\%) was greater than boro-2014 (65.82\%) and boro-2015 $(69.14 \%)$. Howerver, among boro seasons, the mean performance of boro-2015 was better than boro-2014 (Fig.3). Relative water content was found to be lower in rice seedlings in both boro seasons than kharif in most of the genotypes (Fig. 3). Only few genotypes showed almost similar relative water content in all the three seasons. Singh et al. (2012) reported that chilling stress reduces relative water content in maize plants which is in agreement with the present study in case of rice.

Among parental genotypes, Gautam showed highest membrane stability index in boro-2014 $(82.40 \%)$ and boro-2015 (85\%). In kharif-2015, Jaya (86.53\%) exhibited highest membrane stability index. The membrane stability index ranged from $55.90 \%$ (HUR $36 \mathrm{x}$ Jaya) to $82.20 \%$ (Krishna Hamsa $\mathrm{x}$ Gautam) in boro$2014,55.43 \%$ (IR $8 \times$ IR 36) to $80.90 \%$ (MTU 1010 x Jaya) in boro-2015 and $60.88 \%$ (IR $8 \times$ IR 64) to 87.2 $\%$ (IR 64 x Krishna Hamsa) in kharif-2015. The mean performance of kharif-2015 (78.16\%) was greater than boro-2014 (69.92\%) and boro-2015 (71.06\%). Howerver, among boro seasons, the mean performance of boro-2015 was better than boro-2014 (Fig. 4). Yamada et al. (2004) reported that most of the plants show high degree of membrane damage when exposed to cold stress. Habibi et al. (2011) also reported that cold stress significantly affected the cell membrane system in wheat cultivars. In the present study, membrane stability index was relatively lower in both boro seasons in comparison to kharif season (Fig. 4).

Correlation studies showed significant and positive correlation among survival per cent, chlorophyll content, relative water content and membrane stability index over seasons (Table 3).

\section{Conclusion}

In the present study, most of the parents and crosses showed better performance in kharif than both boro seasons for the studied traits. This may be due to low temperature stress condition during the seedling stage 
in boro season. To generate appropriate genotypes for boro season evaluation of seedlings for cold tolerance is important. The genotypes scored in cold tolerant groups may be used as breeding material in boro seasons. Most of the cold tolerant genotypes exhibited high survival per cent, high chlorophyll content, high relative water content and high membrane stability index than the susceptible ones.

\section{ACKNOWLEDGEMENTS}

The first author is grateful to the Department of Science and Technology, New Delhi, India for financial assistance as INSPIRE Fellowship and Department of Genetics and Plant Breeding, Banaras Hindu University, Varanasi for providing facilities for conduct of experiments during the course of present study.

\section{REFERENCES}

Aghaee, A., Moradi, F., Zare-Maivan, H., Zarinkamar, F., Irandoost, H. P. and Sharifi, P. (2011). Physiological responses of two rice (Oryza sativa L.) genotypes to chilling stress at seedling stage. African J. Biotechnology, 10: 7617- 7621

Basuchaudhuri, P. (2014). Cold tolerance in rice cultivation. CRC Press, Taylor \& Francis Group, 6000 Broken Sound Parkway NW, Suite 300, Boca Raton.

Dutta, D. and Pathak, P. K. (2007). Response of assam rice varieties to low temperature stress. Journal of Plant Genetic Resources, 20(1): 57-63

Habibi, F. Normahamadi, Sharifabad, H., Eivazi, A. and Heravan, M. (2011). Effect of cold stress on cell membrane stability, chlorophyll $\mathrm{a}$ and $\mathrm{b}$ contain and proline accumulation in wheat (Triticum aiestivum L.) variety. African Journal of Agricultural Research, 6(27): 58545859

IRRI (2002). Standard evaluation systems for rice. International rice research institute, Metro City Manila, Philippines, 35
Jan, M., Shinwari, K. I., Shah, G., Khan, M. H. U., Ullah, S., Hameed, A. and Malook, I. (2015). Consequences of short term low temperature stress on physiological and biochemical aspects of rice (Oryza sativa L.). Scientia Agriculturae, 10 (1): 1-14

Mata, C. G. and Lamattina, L. (2001). Nitric Oxide induces stomatal closure and enhances the adaptive plant responses against drought stress. Plant Physiology. 126: 1196-1204

Pathak, P. K., Saud, R. K., Bora, D. K., Singh, K. D. and Pathak, A. K. (1999). Status of boro rice in Assam: A case study. International Rice Commission Newsletter, 48: $60-66$

Priyanka, K., Jaiswal, H. K., Waza, S. A. and Sravan, T. (2015). Response of rice seedlings to cold tolerance under boro conditions. SABRAO Journalof Breeding and Genetics, 47 (2): 185-190

Sairam, R. K., Rao, K. V. and Srivastava, G. C. (2002). Differential response of wheat genotypes to long term salinity stress in relation to oxidative stress, antioxidant activity and osmolyte concentration. Plant Science, 163: 1037-1046

Singh, I., Kumar, U., Singh, S. K., Gupta, C., Singh, M. and Kushwaha, S. R. (2012). Physiological and biochemical effect of 24-epibrassinoslide on cold tolerance in maize seedlings. Physiol Mol Biol Plants, 18(3): 229-236

Yadegari, L. Z., Heidari, R. and Carapetian, J. (2007). The influence of cold acclimation on proline, malondfialdehyde (MDA), total protein and pigments contents in soybean (Glycine max) seedling.J. Biol. Sci., 7(8): 1141 $-1436$

Yamada, T., Jones, E. S., Congan, N. O., Vecchies, A. C., Nomura, T. and Hisano, H. (2004). QTL analysis of morphological, developmental, and winter hardinessassociated traits in perennial ryegrass. Crop Sci., 44: 925-935

Yoshida, S. (1981). Fundamentals of rice crop science. International Rice Research Institute, Los $\mathrm{Ba} \sim$ nos. 1-63 